\title{
INTRODUCTION TO THE SPECIAL ISSUE: PAPERS FROM THE CONFERENCE "RECENT ADVANCES IN THE ARCHAEOLOGY OF EAST AND SOUTHEAST ASIA"
}

\author{
Nam C. Kim ${ }^{1}$ and Alison K. Carter ${ }^{2}$ \\ ${ }^{1}$ Department of Anthropology, University of Wisconsin-Madison,nckim2@wisc.edu \\ ${ }^{2}$ Department of Anthropology, University of Wisconsin-Madison, alisonkyra@gmail.com
}

This special issue of the Journal of Indo-Pacific Prehistory Association presents some of the results of a small conference entitled "Recent Advances in the Archaeology of East and Southeast Asia." The event was held in Madison, Wisconsin, and brought together a collection of scholars from the US and abroad (Figure 1). Organized by Nam Kim and Alison Carter, the conference was hosted at the University of Wisconsin-Madison (March 15-16, 2013), and was jointly sponsored by the Department of Anthropology, the Center for East Asian Studies, and the Center for Southeast Asian Studies.

As reflected by the conference theme and its list of participants, the papers covered a wide gamut of topics along different geographic, theoretical, and chronological parameters. Although they represented only a small sample of archaeological research being conducted in East and Southeast Asia, the papers clearly demonstrated the enormous breadth, accelerating pace, and high quality of research programs currently being pursued in these connected areas. The dialogue fostered by this gathering was stimulating and engaging, and it demonstrated to both participants and audience members the exciting prospects for continued advancement of our archaeological knowledge of this part of the world.

Some of the notable topics related to: cutting-edge analytical methods of laboratory analysis on various ancient technologies and materials; innovative approaches to patterns of trade and conflict; cross-regional comparisons of hunting/gathering/fishing societies; intersections between modern-day politics and cultural heritage; and reconsiderations of the wider region's forms of complexity, monumentality and urbanism.

All of the participants agreed that the wide array of papers showed that data from the regions will not only help to broaden our understanding of the area's archaeological past, but will also place important cases within a larger purview of history and social change. Made abundantly clear from the papers was how East and Southeast have been long interlinked to one another, and how they were in turn linked to a global geographic setting.

As many of the papers presented have appeared and will appear in other publications, this special issue presents papers by Francis Allard, Li Liu, Lisa Niziolek, Hyung Il Pai, and Trinh Hoang Hiep. The paper by Trinh has since added a co-author, Damien Huffer (Smithsonian
Institution), and has been updated. A full listing of the titles of each presented paper appears at the end of this introduction. We are also delighted to include concluding thoughts by Stark, in which she broadly assesses the current state of archaeological research and some of its recent and exciting lines of inquiry.

In summary, we would like to express our appreciation to all of the participants and attendees and to Mark Kenoyer for initially securing funds for the gathering. We also wish to thank the former and current editors of the Journal of Indo-Pacific Prehistory, Ben Marwick, Peter Lape, and Oli Pryce, for offering a venue and valuable assistance in putting this issue together. We are indebted to the Henry Luce Foundation, and particularly to Helena Kolenda, for generous funding that made this special event possible. Over the years the Henry Luce Foundation has been instrumental in advancing much of the archaeological work being done in East and Southeast Asia. We look forward to the continued growth and development for this wonderful field of research, and hope that the various lines of inquiry showcased at the conference will continue to shape our understanding of this significant area of the world.

\section{LIST OF PAPERS PRESENTED AT THE "RECENT ADVANCES IN THE ARCHAEOLOGY OF EAST AND SOUTHEAST ASIA" CONFERENCE}

Francis Allard (Indiana University of Pennsylvania) The Han empire's southern borderlands: Perspectives from archaeology and history

Bui Van Liem (Vietnam Institute of Archaeology) New achievements in Vietnamese archaeological research for cultural heritage

James Burton (University of Wisconsin-Madison) The use of isotopes in dental enamel to investigate human mobility in eastern China during the Shang Dynasty

Alison Carter (University of Wisconsin-Madison) Glass Artifacts at Angkor: Evidence for exchange?

Junko Habu (University of California, Berkeley)

Jomon Food Diversity and Long-Term Sustainability: Lessons from Prehistoric Japan 
Mitch Hendrickson (University of Illinois at Chicago) Dating the end of industry? Assessing the history of iron production within the Angkorian period center of Preah Khan of Kompong Svay, Cambodia.

Zhichun Jing (University of British Columbia) Shang urbanism and the evolution of simplicity

Laura Junker (University of Illinois at Chicago) Conflictive trade, value and power relations in Philippine maritime trading polities of the 8th-19th century Philippines

J. Mark Kenoyer (University of Wisconsin-Madison) Stone beads from Anyang and Houma: New perspectives on Shang and Zhou ornament traditions

Peter Lape (University of Washington)

Causes of incipient warfare in protohistoric island Southeast Asia

\section{Qinglin Li (Wuhan University, China)}

Technics of earthen water pipes from the Yinxu Site, remains of a capital of the late Shang Dynasty

Li Liu (Stanford University)

Rethinking Neolithization in North China: Microscopic analyses of plant processing on grinding stones
Lisa Niziolek (Field Museum, Chicago)

Early Trade along the maritime Silk Road in East and Southeast Asia: A view from the Java Sea Wreck

Ben Marwick (University of Washington)

The Hoabinhian of Southeast Asia and its relationship to global Pleistocene lithic technologies

Hyung Il Pai (University of California, Santa Barbara) Gateway to Korea: Colonialism, nationalism, and reconstructing ruins as tourist landmarks (1905-2012)

Miriam Stark (University of Hawaii-Manoa) Introductory Remarks

James Stoltman (University of Wisconsin-Madison) New insights into the composition of ceramic molds, models, and cores associated with the production of Chinese bronzes

Trinh Hoang Hiep (Vietnam Institute of Archaeology) Da But culture in Vietnam

Alice Yao (University of Chicago)

Monumentality in the Bronze Age of southwest China

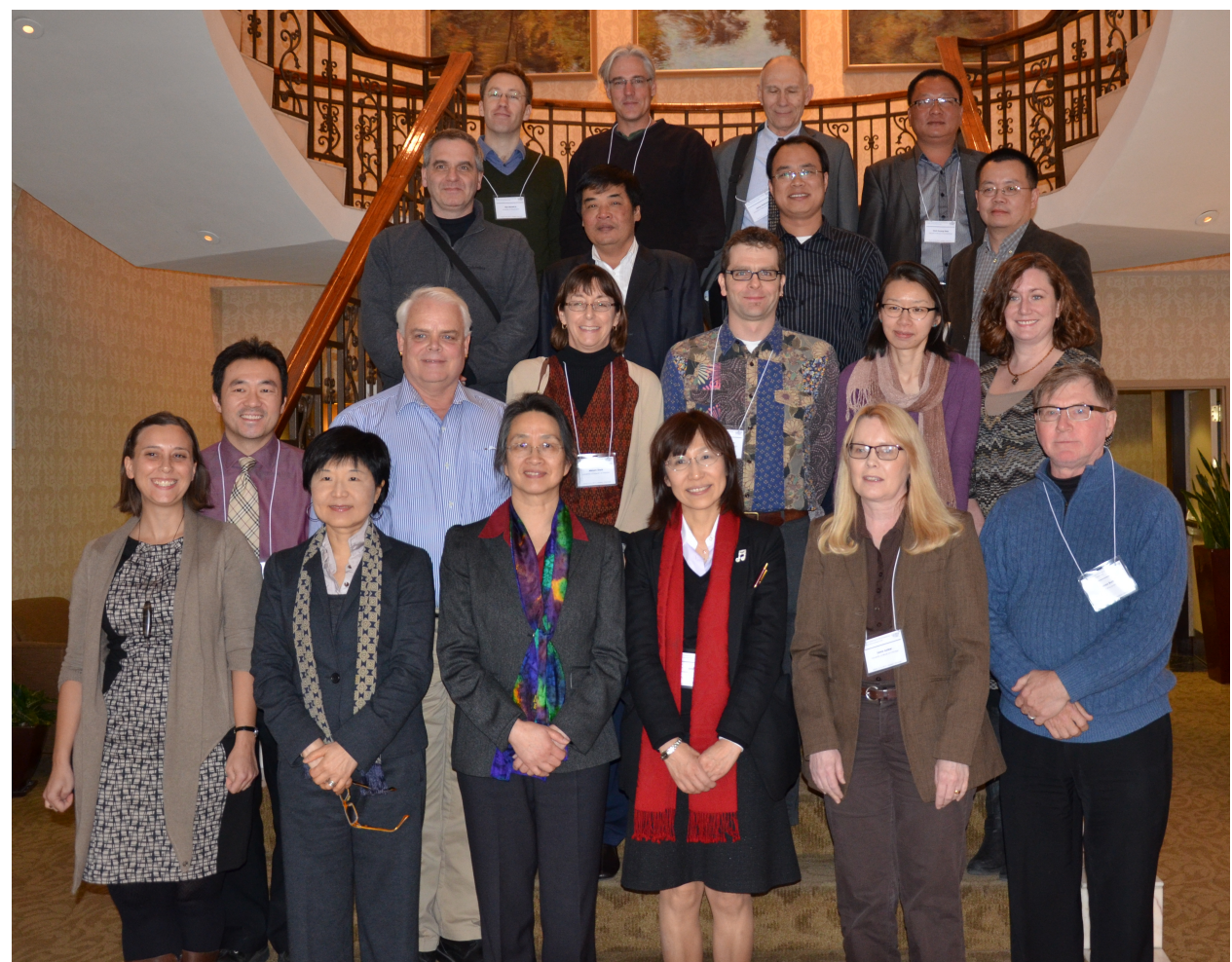

Figure 1: Conference participants from left: (top row) Ben Marwick, Peter Lape, James Stoltman, Trinh Hoang Hiep; (second row) Francis Allard, Bui Van Liem, Qinglin Li, Zhichun Jing; (third row) Nam C. Kim, J. Mark Kenoyer, Miriam Stark, Mitch Hendrickson, Alice Yao, Lisa Niziolek; (fourth row) Alison Carter, Hyung Il Pai, Li Liu, Junko Habu, Laura Junker, and James Burton. 